\title{
A Conversation Analysis on the Interview between Agnez Monica and Host in "Build Talk Show"
}

\author{
T. Thyrhaya Zein ${ }^{1}$, Ronobel Boston Silalahi ${ }^{1}$, Muhammad Yusuf ${ }^{1}$ \\ ${ }^{1}$ English department, Universitas Sumatera Utara, Medan, Indonesia \\ Correspondence: T. Thyrhaya Zein, English Department, Universitas Sumatera Utara, Jl. Universitas No. 19 Kampus \\ USU, Medan, Sumatera Utara, 20155, Indonesia.
}

Received: April 25, 2021

doi:10.5430/wjel.v11n2p52
Accepted: July 26, $2021 \quad$ Online Published: August 4, 2021

URL: https://doi.org/10.5430/wjel.v11n2p52

\begin{abstract}
The aim of the study is to determine how the aspects of conversational interactions are realized in the conversation. The researcher collects and analyzes data by applied qualitative content analysis through documentation technique. The data of this study were the utterances while the source of data is a video of the interview between the interviewer (Kevan Kenney) and the interviewee (Agnez Monica a.k.a Agnez Mo) in Build Talk Show. The source of the data was downloaded from the official Youtube channel of Build Talk Show with a duration of 27:03 minutes. The data analysis is based on the theory of conversation analysis proposed by Paltridge. The results of this study show that the interviewer (Kevan Kenney) employed the aspects of conversational interactions in asking and responding to the questions of the interviewee. The aspects of conversational interactions such as opening conversation, adjacency pairs, preference organization, turn taking, and feedback were used. Where as, closing conversation and repair categories were not used by interviewer throughout the conversation. On the other hand, the interviewee used Turn Taking, Feedback and Repair, but Opening and Closing Conversation, Adjacency Pairs, and Preference Organization were not used by the interviewee throughout the conversation. So, five of seven aspects of conversational interactions in conversation are applied. Those aspects of conversational interactions are realized in this conversation because it is the standard in conversation, and the interviewer and interviewee applied the aspects of conversational interactions in order to seek the information from the interviewee, to give the clarification of the issues and make a good communication in that conversation.
\end{abstract}

Keywords: conversation analysis, interview, build talkshow

\section{Introduction}

Conversation is used to form interactions between humans and form social relationships. A good conversation occurs when both parties know when it is their turn to speak and understand the intentions because only through a conversation can the two parties find the same meaning. According to Hutcby and Woffitt (1998), conversation analysis (henceforth CA) concerns with the problem of social order and how language is created by social context. Conversation analysis looks at everyday conversation and how people manage interaction. It seeks to understand real interaction between people. The smoothness of interaction also depends on the interactants (Hanafiah, Mono \& Yusuf, 2021).

People can understand how interaction unfolds from CA. Sidnell (2010) states that CA aims to describe, analyze, and understand talk as a basic and constitutive feature of human social life. It means that CA is concise and clear basis for describing, analyzing, and understanding human speech. In CA, a particular attention is given to everyday spoken interaction. Seedhouse (2005) states that the speakers involved in CA can interpret each other, action, and develop shared understanding of the progress of the interaction. The conversation in interview is constantly shifting between information and entertainment. This genre comprises a series of short interviews and occasionally also a performance mainly used in the entertainment industry. Interview is a communication between two people to exchange information and ideas through question and answer, so that meaning can be constructed in certain data. Interview is one of the methods of collecting data to obtain information by asking respondents directly. Therefore, the ability of an interviewer must be good from all aspects in speaking, behaving, and socializing.

In certain situations, interview can be conducted by way of direct meetings between individuals, in writing, by telephone, or by interviewing simultaneously, in the form of a discussion group. There are two or more individuals 
involved in this process, including that of the host as the interviewer and the guest as the interviewee. There are two basic ways of handling interviews. One is designed for extended interviews and the other is for short interview segments. Those are regarded as the common types of interviews. Some local television and cable stations have interview programs in which famous people are interviewed. This is referred to as a soft interview that focuses on the personality rather than the hard news issues.

A talkshow is a television program that usually involves famous people in the form of interviews or simple conversations. Sometimes, members of the audience have problems understanding the conversations that occur in talk show interviews because sometimes there are complex interpretations of their conversations. Talk shows have more recently started to appear on internet. Also, several Internet blogs are in talk show format including the "Build Talk Show". BUILD talk show, formerly called American Online Build Speaker Series, is a live interview series that focuses on the biggest names in entertainment, fashion and business. One of the viral talk shows is between the international singer from Indonesia, Agnez Monica (a.k.a Agnez Mo) and the host from Build talk show, Kevan Kenney. So, the aim of the study is to determine how the aspects of conversational interactions are realized in the conversation.

\section{Literature Review}

The conversation interactions consist of openings and closings, turn taking, sequences of related to conversation interactions. Conversation analysis is more about the structure of the conversation than the message conveyed, it focuses on the context of the utterances. Conversation Analysis seeks to understand real interaction as it happens and unfolds. This article used CA theory based on Paltridge (2012) which consists of adjacency pairs, turn taking, preference organization, opening conversation, closing conversation, repair, and feedback.

In doing a conversation, there is a need for the relation between the first utterance and second utterance. Adjacency pair is about natural reaction to someone's utterances, the reaction may lead the conversation in a certain direction. The pattern in adjacency pairs determines the meaning conveyed and minimizes misunderstanding between participants.

The turn taking between two speakers is used in doing conversation. Turn taking with nomination means the speaker gives a signal to the next speaker to respond to conversation while the turn taking without nomination means the next speaker gives statement or opininon without a signal. The response to another speaker is named as preference organization. The response consists of preferred response and dispreferred response. Preferred response means when the second fair part is related to the firs fair part such as acceptance, agreement, and expected answer. Dispreferred response represents refusal, disagreement, and unexpected answer.

In doing conversation, feedback is used by the listeners to express their attention. It can be indicated by the utterances such as 'yeah' and a listener can also express it by modifying some of the utterances that the speaker has delivered. Related to the aspects of conversation analysis is Repair. Repair is the way a speaker fixes the utterances they or someone else has said. It also helps the listener and the speaker in listening, speaking, or understanding a problem. Paltridge (2012) stated that Repair consists of Other Repair and Self Repair. Other repair means when the listeners correct the speaker's utterances, while self repair means when the speakers themselves correct their own utterances.

\section{Research Method}

This study used qualitative research method. The aims of this study were analyze and identify the aspects of conversational interactions in the interview. The utterances of the interviewer and interviewee are transcribed and analyzed to categorize them by function.

\subsection{The Sources of Data and the Data}

The data of the study are utterances of the interview between the interviewer (Kevan Kenney) and interviewee (Agnez Monica). The source of the data was the video was downloaded from https://www.youtube.com/watch?v=skqtsF1-3IQ\&t=330s, it is published on November 23rd 2019, and the duration was 27 minutes and 03 seconds.

\subsection{Instruments}

The data are collected by using documentation method. Thus, the researcher used the following instruments to collect data: first, the researcher downloaded the video from official Youtube https://www.youtube.com/watch?v=skqtsF1-3IQ\&t=330s. Second, the researcher listened to the data interview and transcribed it into a written form. The utterances of the interviewer and interviewee are transcribed and analyzed to 
categorize them by function using CA proposed by Brian Paltridge. The third step pays close attention to the conversation's utterances. The fourth step is to choose them based on aspects of conversational interactions, and the final step is to find the conversational aspects of the utterances used by the interviewer and interviewees.

\subsection{Data Analysis}

This research uses qualitative content analysis proposed by Patton (2002). This study applies several steps, such as to prepare the data, define the unit of analysis, describe the data and draw a conclusion. The researcher prepared the data for qualitative content analysis (Patton, 2002) before analyzing the conversation. The researcher developed the analysis unit by defined the interviewer and interviewees' utterances that comprise aspects of conversational experiences are described using Paltridge (2012). Furthermore, the researcher developed a classification and coding scheme. These include the following: adjacency pairs as AP, preference organization as PO, opening conversation was coded OP, turn taking as TT, feedback as F, repair as R, and closing conversation as CC. The researcher coded all aspects of conversational interactions found in the conversation in the fourth step that was coding all texts. The data are numbered, written in italic, and the IR and IE codes are used to distinguish between the interviewer and the interviewee.

\section{Findings}

The interviewer (Kevan Kenney) (henceforth KK) uses the aspect of conversational interaction in terms of giving and responding to questions to the source. The aspects used are Opening Conversations, Adjacency Pairs, Preference Organization, and Turn Taking. However, Feedback, Repair and Closing Conversation are not used by interviewer throughout the conversation in the interview. Then, interviewee (Agnez Monica) (henceforth AM) used adjacency pairs, preference organization, turn taking, feedback, and repair. Then, opening and closing conversation were not used by interviewee throughout the conversation in the interview. The number and types of conversational interactions found in this conversation, the following: opening conversation 1 time, adjacency pairs 10 times, preference organization 10 times, turn taking 119 times, feedback 13 times, and repair 2 times. The aspect most used in this research is Turn Taking, and the least used is the opening conversation. This happens because the research was conducted on two people who were having a conversation so that there are consists a lot of Turn Taking. The data was shows with table below:

Table 1. Elements of Conversation Analysis

\begin{tabular}{ccc}
\hline No & Aspects of Conversation Analysis & TM \\
\hline 1 & TT & 119 \\
2. & PO & 10 \\
3 & AP & 10 \\
4 & F & 13 \\
5 & R & 2 \\
6 & OC & 1 \\
\hline
\end{tabular}

\subsection{Adjacency Pairs}

In conversation, pairs of utterances are often interdependent. They are thought to be automatic sequences that have a first and second part. The researcher found adjacency pairs ten (10) times in the interview between Kevan Kenney as the interviewer and Agnez Mo in Build Talk Show.

Table 2. Percentage of Adjacency Pairs

\begin{tabular}{cccc}
\hline NO & Types of Adjacency Pairs & TM & \% \\
\hline 1. & $\mathrm{Q} \pm \mathrm{A}$ & 5 & 50 \\
2. & $\mathrm{C} \pm \mathrm{Acc}$ & 3 & 30 \\
3. & $\mathrm{R} \pm \mathrm{Ag}$ & 1 & 10 \\
4. & Ass $\pm \mathrm{Ag}$ & 1 & 10 \\
\hline
\end{tabular}

The types of adjacency pairs most used in the interview is Question - Answer. The results combine Question Answer 50\%, Compliment - Acceptance 30\%, Request - Agreement 10\%, and Assessment - Agreement 10\% from all pairs. 


\subsubsection{Question-Answer}

Question can be shown with the expression of someone's curiosity about information that is put in an interrogative sentence. In Build Talk Show, KK gives some questions to AM.

Excerpt 29 - 30;

KK : Why right now? What was about the energy of this moment that you thought it was perfect to release the song?

AM : I think it because I promised my self in 2020, I'm gonna put up more songs, and I think it just the first thing to do. Yeah, it's the right time. You know the fans have been asking for it, and I couldn't really hold it anymore. Like I was literally I was in the studio, I played it on IG story, and people were like " oh my God, Agnez you know you wrote that seven years ago...." I actually totally forgot that it was seven years ago but of course my fans...

The question type is indicated because KK expresses: "Why right now? What was about the energy of this moment that you thought it was perfect to release the song?" The word "why' means KK would like to get information or reason of something. That utterance means that KK would like to get the information of the reason why AM release the song. In addition, the characteristics of question form has the word of what, who, where, when, why, and how $(5 \mathrm{~W}+1 \mathrm{H})$. In that sentence, the words 'why' and 'what' are used by the interviewer KK. Thus, the question type is used by the interviewer. Then AM responded to it by saying "I think it because I promised myself in 2020, I'm gonna put up more songs, and I think it is just the first thing to do." It means that AM as the interviewee answers the question from $\mathrm{KK}$ as the interviewer. The utterance indicated by the type of Answer. It means that AM responded it with expected answer. Therefore, Question - Answer is realized in this excerpt.

\subsubsection{Compliment Acceptance}

Compliment is the way of praising another person about something he or she does. It is responded with acceptance. In Build Talk Show, KK as host gave a compliment to AM for her work and her fashion in the interview.

Excerpt 9 - 10;

KK : It is because you were so huge at the time you've even been bigger now and I feel like you've just done so much since 2017.

AM : Yeah, I think so too because I think that was when I release $\mathrm{X}$ album.

KK as the interviewer would like to praise AM about the achievement she did between 2017 to 2020 by saying "It is because you were so huge at the time you've even been bigger now and I feel like you've just done so much since 2017'. This conversation, AM seems accept the compliment from KK as the interviewer responded with I think so too because I think that was when I release X album. It is indicated as one of the expression of acceptance. Therefore, Compliment - Acceptance is used in this conversation.

\subsubsection{Request Agreement}

Requesting is asking someone to do something which can be responded with acceptance or refusal. A request becomes part of the Adjacency Pairs aspect when someone gives a request to another person and that person approves the request. In Build Talk Show, KK as the host gives a request to share experience from AM.

Excerpt $27-28$;

KK : Can you tell me the story?

AM : So I think I wrote it the first time I go to LA, and I work with Tierce, which is the producer and also Frankie, and it was just like one of those days where we like you know I want to write something that just feels good. You know I want to talk about being in love, and we just decided to keep it because I thought like you know, that that's a special one but yeah we never really got to put it out, but I just feel like the fans deserve that, I deserve that because that's like my little baby.

In this excerpt, KK used requesting expression to AM. It indicated by the utterance Can you tell me the story? And then AM responded it with agreement expression. Therefore, Requesting Agreement expression is used by the interviewees, which is one of the types of Adjacency pair. Then AM responded the expression of agreement that is represented by saying So I think I wrote it the first time I go to LA, and I work with Tierce, which is the producer and also Frankie, it means AM agreed to provide the story that requested by KK as the interviewer. Therefore, requesting - agreement is realized in this conversation. 


\subsubsection{Assessment Agreement}

In Build Talk Show, KK as the interviewer gives an assessment to AM as the interviewee. An assessment is part of adjacency pairs when someone gives an assessment to other person and the other person agrees with it.

Excerpt 113 - 114;

KK : You know all the critics, right, You're not enough of this, you're not enough of that. How is all that pushing and pulling informed your short of evolution as an artist? How have you short of like found yourself within all that? because there's so many opinions about you when you when you're as big as you are.

AM : Umm, I think it just kind of look at it as a learning process and I never wanted to hide that anyway, you know what I mean like I always share that with my fans that I'm" hey, I'm evolving as human being", you know I'm not always perfect and I'll be the first person to admit that.

KK gave an assessment to AM about her opinion in critics of her song by asking two question that is How is all that pushing and pulling informed your short of evolution as an artist? And How have you short of like found yourself within all that?. While AM responded it with Agreement statement by saying I think it just kind of look at it as a learning process and I never wanted to hide that anyway, you know what I mean like I always share that with my fans that I'm" hey, I'm evolving as human being", you know I'm not always perfect and I'll be the first person to admit that. It means that AM agreed with the statement and question from KK. Therefore, Assessment - Agreement is used by the interviewer in this conversation.

\subsection{Turn Taking}

In a conversation, there is a situation where a speaker takes his or her turn to talk. Turn-taking allows speakers to converse in a more fluid manner, ensuring that no one speaker dominates the discussion. In Build Talk Show, there were two speakers, KK as the host and AM as the interviewee. In Build Talk Show, the speakers gives nomination to talk and several times the two speakers talk at the same time.

Table 3. Percentage of Turn Taking

\begin{tabular}{cccc}
\hline No. & Speakers & Turn Taking & Percentage \\
\hline 1. & KK & 59 & 49.5 \\
2. & AM & 60 & 50.5 \\
\hline & Total & $\mathbf{1 1 9}$ & $\mathbf{1 0 0}$ \\
\hline
\end{tabular}

From table above, it can be seen that the turn appeared most often is AM had 60 turns (50.5\%) and KK had 59 turns $(49.5 \%)$. The total turns in the conversation were 119 turns. It can be seen this conversation is interviewee oriented because the interviewee had most turns in the conversation. This conversation can be divided into two types of Turn Taking.

\subsubsection{The Turn Taking by Giving Nomination}

The turn taking by giving nomination indicated when the first speaker finishes asking a question or offering an opinion to other speakers, the first speaker wishes that the other speaker would like to address or respond to the first speaker, and the other speaker takes his turn by answering the interviewee's or interviewer's question or offering an opinion. An example of how the turn shifted from one speaker to another can be found in the excerpt below.

Excerpt 85 - 86;

KK : Congratulations, but also what is the greatest achievement in your mind that that song did?

AM : Umm, I think it just made me realize that music transcends you know where you come from your skin

tone, your body type, and that's really encouraging you know. Cause when I came out here umm I remember walking into a lot of sessions with you know people stranger at me like oh but you don't like you get it you know. I mean like you don't look a certain way, you know. You don't fit into the stereotypes, and I don't know how many times I have to explain until I was actually tired of explaining. I was just like you know what fuck it. I'm just gonna do it you know, and then if you if you fuck what are you fuck what if you'd not it's fine-it's still me. Um but yeah I mean it's really encouraging you know, like whenever I talk to people to to the radio people about overdose, um they don't just like they can relate to the music they can relate to the song, but but I think the most important thing is they can relate to me because it's 
such an embodiment of American dream if you think about it you know, um so yeah.

From the excerpt above, KK ended his turn by asking with saying what is the greatest achievement in your mind that that song did? and hoping that AM would like to give a response about the question. So, AM began her turn by responding to the question. In this excerpt, KK used the turn-taking aspect, which marked by asking AM as the guest. There for turn change by giving nomination is used by the interviewer Kevan Kenney.

\subsubsection{The Turn Taking without Nomination}

The Turn Taking without nomination indicated when the first speaker finished making a comment to the other speaker without giving a hint or instruction to respond the question or express an opinion and then the other speaker took her turn by expressing an opinion on the first statement. The following extract shows an example of how the turn was switched from one speaker (KK) to the other (AM):

Excerpt $117-118$;

KK : No, I know the answer to that is probably gonna change day by day right, because..

AM : Yeah, Yeah, I mean cause I mean at the end of the day you can't satisfy everybody you know, I just want to make sure that I'm good in front of the Lord, you know like God sees me as good person, I do good thing in life. I try to inspire people to be better, that's that's one of the most important thing.

From to the excerpt above, KK ended his turn by making his statement without providing any additional information to AM. After that, AM took her turn, responding to KK's comment and expressing her opinion. It means overlapping is indicated in this conversation. It is realized with AM started her opinion while KK still giving an opinion. Therefore, the Turn Taking without nomination type is used by the interviewee Agnez Monica.

\subsection{Preference Organization}

The preference organization extends beyond the adjacency pairs. Preference organization is a pair that allows the speaker to choose whether the first pair element is preferred or dispreferred. In Build Talk Show, the researcher discovered a total of 10 preferences in the conversation. In the interview, KK as the host and AM give a preferred and dispreferred response to each other.

Table 4. Preference Organization

\begin{tabular}{|c|c|c|}
\hline No & Preference & TM \\
\hline 1. & Preferred Response & 7 \\
\hline 2. & Dispreferred Response & 3 \\
\hline & Total & 10 \\
\hline
\end{tabular}

In PO, it can be shown that there are preferred and dispreferred responses, as seen in the table above. The preferred response explains how the interviewee responded positively or directly to the interviewer. Dispreferred, on the other hand, is the polar opposite to the preferred one. In this response, the interviewee expresses a negative reaction, such as disagreeing with or refusing to accept the statement. Sometimes, the speakers avoid the dispreferred altogether by means of pre-sequences which is prompt some sort of alternative action on the part of the other participants. The dispreferred response means when the speakers disagree to give the pair of utterances, and there are other intentions between the speakers or the speakers still think about earlier topic.

Table 5. Preferred and Dispreferred Response

\begin{tabular}{cccc}
\hline No. & First Part & Second Part & TM \\
\hline 1. & Request & Acceptance & 1 \\
2. & Assessment & Agreement & 1 \\
3. & Question & Expected Answer & 5 \\
& & Unexpected Answer & 3 \\
\hline
\end{tabular}

The researcher would like to explain the first and second component classes in some data examples below based on the data above: 


\subsubsection{Request Acceptance}

Requesting is the act of asking others to do something and receiving a positive or negative response. In good conversation, a request needs to be responded to, whether it is preferred or dispreferred response. In Build Talk Show, AM gives a preferred response to the request from $\mathrm{KK}$ as the host.

Excerpt $27-28$;

KK : Can you tell me the story?

AM : So I think I wrote it the first time I go to LA, and I work with Tierce, which is the producer and also Frankie, and it was just like one of those days where we like you know I want to write something that just feels good. You know I want to talk about being in love, and we just decided to keep it because I thought like you know, that that's a special one but yeah we never really got to put it out, but I just feel like the fans deserve that, I deserve that because that's like my little baby.

From the excerpt above, it can be seen that KK as the host expressed the request by saying "Can you tell me the story?" and AM responded it by providing the information that KK had requested. AM used preferred response by accepting the request. It means that Request - Acceptance is realized in this interview.

\subsubsection{Assessment Agreement}

Opinion seek or statement, which is asking for another's opinion or approval, may be generated from assessment. It is met with agreement or is referred to as providing an opinion. In Build Talk Show, there was preferred response by $\mathrm{AM}$ and it happens when $\mathrm{KK}$ gives an assessment to $\mathrm{AM}$ as the interviewee.

\section{Excerpt 113 - 114;}

KK : You know all the critics, right, You're not enough of this, you're not enough of that. How is all that pushing and pulling informed your short of evolution as an artist? How have you short of like found yourself within all that? Because there's so many opinions about you when you when you're as big as you are.

AM : Umm, I think it just kind of look at it as a learning process and I never wanted to hide that anyway, you know what I mean like I always share that with my fans that I'm" hey, I'm involving as human being", you know I'm not always perfect and I'll be the first person to admit that.

From the excerpt above, it can be seen that $\mathrm{KK}$ as the interviewer gave two assessments to $\mathrm{AM}$ as the interviewee. Those are to provide the an opinion about How is all that pushing and pulling informed your short of evolution as an artist? And how have you short of like found yourself within all that? While AM as the interviewer responded it with agreement expression by providing the answer from those questions. It means that AM as the interviewee used preferred response by answering the question. Therefore, Assessment - Agreement as preferred interaction is realized in this interview.

\subsubsection{Question Answer}

The word "question" can be used to mean "knowledge seeker," "clarification seeker," and so on. It's about asking someone a question. It is responded to with facts, clarification, and so on. In Build Talk Show, there were also some dispreferred response. KK gives a dispreferred response through the question from AM as the interviewee.

Excerpt $14-15$

AM : Been busy, busy is good, what how would you too?

KK : What what about me? From the excerpt above, it can be seen that KK as the interviewer asked the question by saying, what how would you too? then AM answered it by saying What what about me?

In this conversation, AM responded it with unexpected answer. She responded the question by asking another question. In this conversation, AM used dispreferred response by answering the question with another question. It means that $\mathrm{AM}$ as the interviewer had other intention by asking another question to $\mathrm{KK}$ as the interviewer. $\mathrm{AM}$ as the interviewee used dispreferred response by answering the question according to what was asked by the interviewer. Therefore, Question - Answer is used by the interviewer and interviewee.

\subsection{Feedback}

The ways in which speakers give input to each other are referred to as feedback; that is, the ways in which listeners demonstrate that they are paying attention to what is being said. Feedback can be conveyed by paraphrasing what the other person has just said, as well as by body language and eye contact. In Build Talk Show, there were several times 
$\mathrm{KK}$ as the host and $\mathrm{AM}$ as the interviewee gave feedback to each other's opinion.

Excerpt $13-14$

KK : You've been busy

AM : Been busy, busy is good, what how would you too?

From the excerpt above, it can be seen that KK and AM expressed or responded the question and statement by using Feedback expression. It indicated by AM paraphrasing KK's statement by saying Been busy, busy is good. Therefore, feedback interaction is realized in this conversation.

4.5 Repair

\subsubsection{Self Repair}

In a conversation, self-repair is the speaker's way of correcting what she or he has said and double-checking what she or he has understood. It was found in Build Talk Show

Excerpt 20;

AM : I know, and I mean probably live here for like three months or six months. I mean look at this, the vibes is kind of New York!

From the excerpts above, it can be seen that AM expressed or maked a statement by using Repair especially Self Repair expression. It indicated by the words 'I Mean.' means that the interviewees sensed that the words were still wrong and decided to correct them in her own. Therefore, Self Repair is used by the interviewees.

\subsection{Opening Conversation}

The opening conversation is used to begin a talking conversation between two or more people. In this interview, Kevan Kenney as the host opened the event in a more casual and informal way. There is just one person used the opening phrase in this conversation, and that person was Kevan Kenney (KK), as the host in this interview. The extract is below, along with an explanation:

\section{Excerpt 1;}

Kevan : what's going on it's Kevan Kenny we were live on the corner of 4th and Broadway for a new edition of the build series and it has been over two years since our guest today has graced the build stage and I'm telling you right now honestly there's not been a week since 2017 well I've not received a tweet a DM if they had my phone number they'd probably be leaving me voicemails to have her back on the show by request she is here today give it up for Agnes Mo

From the excerpt above, it can be seen that KK opened the program by introducing Agnez Mo as the interviewee in the talk show. It indicated the manner in which Kevan Kenney introduced Agnez Mo with an interview to the audience. Therefore, Opening Conversation is realized in the interview.

\section{Discussions}

Based on the analysis, it is found that the conversation in the interview between Agnez Monica and the host in Build Talk Show is a typical one, which means the interviewer and the interviewee do the communication actively. Eventhough, the use of the aspects of conversational interactions particularly in closing conversation not realized in the interview. The result of the previous research by Sitepu, et al. (2019) discussed on the conversation analysis which deals with interview of Prime Minister Julia Gillard in Sky News Australia Channel. It analyzed how the aspects of conversational interactions are realized in the conversation. Sitepu Eka used the utterances from the interviewer and the interviewees as the data of the research. Sitepu Eka analyzed the data by using Conversation Analysis theory proposed by Paltridge (2012) such as opening conversation, adjacency pairs, preference organization, turn taking, and closing conversation. Comparing to the research conducted by the researcher, the aspects of conversation interactions are also found in the conversation, where in this study the researcher used the video of International Singer interview Build Talk Show with Kevan Kenney as the subject and analyzed the aspects of conversational interactions used by the participants and the results are those aspects of conversational interactions realized in this conversation.

In this study, Interviewer of Build Talk Show (Kevan Kenney) used several aspects of conversational interaction to articulate his utterances when asking the interviewee (Agnez Mo). According to Paltridge (2012), there are seven types of conversational interaction in conversation; however, Kevan Kenney used five aspects of conversation. Firstly, Kevan Kenney used Opening Conversation to welcome the interviewee as the host in the interview. It means 
that he used this aspect of conversational interactions once throughout the conversation. Secondly, Kevan Kenney employed Adjacency Pairs in giving and responding the questions to the interviewees including Requesting, Question, and Compliment. It is used by the interviewer because he would like to seek the information and ask the questions about current issues to the interviewees. Thirdly, Turn Taking, Kevan Kenney had fifty nine turns throughout the conversation. The interviewer used Turn Taking aspect in giving opinion and asking the questions to the interviewees. Turn Taking was defined into 2 ways: the one by giving nomination and another without nomination. Fourthly, Kevan Kenney employed Preference Organization in giving and responding the interviewees. Fifthly, Feedback is used and it occurred five times in the interview. It is indicated by the word 'yeah.' However, Repair and Closing Conversation are not used by Kevan Kenney throughout the conversation.

Those aspects are not used by the interviewer because there are no words that need to be corrected. While, Closing Conversation is not used because the interview program was ended with questions from the audience. Therefore, Kevan Kenney used five of seven aspects of conversational interactions in this interview. IE (Agnez Monica) used three aspects of conversation interaction in the interview. Firstly, Agnez Monica used Turn Taking, Agnez Monica had sixty turns throughout the conversation. Secondly, Feedback is used and happened two times. It is pointed by Agnez Monica paraphrasing the interviewer's utterance and by saying yeah.. Thirdly, Repair occurred twice throughout the conversation. Specifically it is Self-repair type. It means Agnez Monica realized to change her utterance into the correct words by herself. However, Opening and Closing Conversations are not used by her throughout the conversation in the interview. Therefore, Agnez Monica used three of seven aspects of conversational interactions in conversation. Those aspects of conversational interactions are realized in the conversation with different characteristics. Repairs are not used by the interviewer, while Opening and Closing Conversation were not used by the interviewee. Those aspects of conversational interactions are realized in this conversation because that is the standard in conversation and the interviewer and interviewees applied the aspects of conversational interactions in order to seek the information from the interviewee--to give the clarification of the issues and to make a good communication in that conversation. It might be stated that both the interviewer and the interviewee are used the aspects of conversational interactions

\section{Conclusion}

Based on findings of aspects of conversational interactions in conversation used on the interview between Agnez Monica as the interviewee and Kevan Kenney as the host in Build Talkshow, there are three conclusions that can be drawn. The interviewer employed the aspects of conversational interactions in giving and responding the questions to interviewee. Opening Conversation, Adjacency Pairs, Preference Organization, Turn Taking and Feedback are used. However, Repair are not used by interviewer throughout the conversation while interviewee used turn taking, feedback and repair. However, adjacency pairs, preference organization and opening and closing conversation are not used by interviewee throughout the conversation. Therefore, five of seven aspects of conversational interactions in conversation are used.

Those aspects of conversational interactions are realized in the conversation with particular characteristics. The interviewer does not use repair. It was not used by the interviewer because the interviewer lacked the required utterances to articulate certain aspects. Opening and closing conversation are not used by the interviewee. Certain elements of conversational interaction are realized in this discussion because they are the norm in conversation, and the interviewer used them to obtain information from the interviewee, to clarify problems, and to maintain effective contact in that conversation. It could be concluded that aspects of conversational interactions are realized by the interviewer and interviewee.

\section{References}

Ali, H. K. (2018). Conversation Analysis of the Structural Units of Interaction in American and Iraqi TV Talk Shows: The Doctors and Shabab Wbanat \| International Journal of Language Academy, 6(2). https://doi.org/10.18033/ijla.3870

Hanafiah, R., Mono, U., \& Yusuf, M. (2021). Code-switching in lecturer-students' interaction in thesis examination: A case study in Indonesia. International Journal of Instruction, 14(1), 445-458. https://doi.org/10.29333/iji.2021.14126a

Hutchby, I., \& Wooffitt, R. (2011). Conversation Analysis (2nd ed.). Cambridge: Polity. https://doi.org/10.1111/j.1467-9841.2009.00430_4.x

Isgianto, L. (2016). The Adjacency Pairs Analysis On Six Minutes English Conversation Script of BBC Learning English: A Study of Discourse Analysis. https://doi.org/10.20961/pras.v0i0.1566

Published by Sciedu Press 
Liddicoat, A. J. (2007). An introduction to Conversation Analysis. London: Continuum.

Paltridge, B. (2012). Discourse Analysis: An Introduction. London: Bloomsbury.

Pillet-Shore, D. (2017). PREFERENCE ORGANIZATION. Oxford Research Encyclopedia of Communication. https://doi.org/10.1093/acrefore/9780190228613.013.132

Prihastuti, Y. S., \& Yusuf, F. N. (2019). Conversation Analysis: Turn Taking Marker in Catatan Nazwa. Atlantis Press. https://doi.org/10.2991/conaplin-18.2019.313

Rahmah, C., \& Muji, N. (2019). Conversation Analysis of Repair In Fox News Sunday Interview Between Chris Wallace and Donald Trump. Medan: University of Sumatera Utara.

Sidnell, J. (2011). Conversation Analysis: An Introduction. West Sussex: Wiley Blackwell. https://doi.org/10.1111/josl.12010

Sipahutar, A. F. (2018). A Conversational Analysis on the Interview Between Oprah Winfrey and Mark Zuckerberg. Medan: University of Sumatera Utara

Sitepu, E. Y. T., Hanafiah., \& Zein, T. (2020). A Conversation Analysis on Interview with Prime Minister Julia Gillard in Sky News Australia Channel. Journal of English Language Teaching and Linguistics. http://doi.org/10.21462/jeltl.v5i3.469

Tikri, D. N. H. (2019). Conversation Analysis and Its Implications to Language Teaching. TARBIYA: Journal of Education in Muslim Society, 6(2), 197-209. https://doi.org/10.15408/tjems.v6i2.15138

\section{Copyrights}

Copyright for this article is retained by the author(s), with first publication rights granted to the journal.

This is an open-access article distributed under the terms and conditions of the Creative Commons Attribution license (http://creativecommons.org/licenses/by/4.0/). 